\title{
Sexually Transmitted Infections
}

\section{Editorials}

\section{Farewell to Gutenberg?}

I too find it difficult to imagine life without a novel on the beach or the $B M F$ in the loo. But the very nature of the imaginative process roots it in the familiar. I fear we are about to enter a world unfamiliar to most of us over the age of 30. Gutenberg is giving way to Gates. And I urge myself to embrace it with a grin. Electronic Sexually Transmitted Infections (STI Online) was born in September alongside other illustrious journals at HighWire Press, a division of the Stanford University's Green Library, whose mission is to "foster research and instruction by providing a more direct link between the writers and readers of scholarly materials". ${ }^{1}$ This is not a gimmick, but an effort to stay one step ahead of the inevitable. As a 19th century philosopher once said, freedom is the recognition of necessity. We chose this path freely but, as pioneers, we want also to influence how things develop.

As with most revolutions the e-revolution is essentially unavoidable. This one has come about because the scientific community believes that scientific research belongs to all. Some original papers are already being put on the web, for all to see, on sites such as the NIH's PubMed Central. It is not a wild guess that in a few years this practice will become universal. Where the peer review process will fit in with this attempt at openness is a subject to which I will return at a later date. Here I hope to whet your appetite.

STI Online contains full text of articles plus tables and figures, published at the same time as the paper version, thus beating the postman by days or even weeks. Personal subscribers to the paper STI will receive STI Online without additional cost or can subscribe the online version for a reduced rate. Institutional subscribers can subscribe to STI Online separately, the price being determined by the size of the institution. STI Online allows you to browse and search STI archives and access full text of articles from February 1998, as well as abstracts and table of contents for earlier issues. References are hyperlinked to Medline abstracts and free full text links are available to journals hosted by HighWire Press. This is clearly a transitional period. In the longer term the paper version and $S T I$ Online will diverge into two different beings, as befits their different natures. We cannot crystal ball gaze too adventurously at this stage, but a recent brainstorming session $^{2}$ came up with some visions. What follows is the output of those brains in "storm" mode.

STI Online will experiment with a more open peer review process, invite readers to comment on selected papers in a more interactive way, invite e-letters, and aim to introduce an interactive continuing medical education (CME) programme, which will be coordinated by Sarah Edwards (consultant in genitourinary medicine, West Suffolk Hospital, UK). As HighWire currently hosts over 200 journals including the $B M F$ and some of the BMJ specialist journals we can create hyperlinks to the full text with related articles in these. We are currently negotiating with our sister journals to see if we can create more direct and dynamic crosslinks between us. Instant free access to Medline could also be augmented by the STI@1ert which will alert readers to important related publications in other journals and to important new websites. These will replace the Current Publications section of the journal. We will create direct links to conference sites allowing instant access to abstracts. There will also be more room for cases of instructive (and not just rarity) value - though concerns for confidentiality and consent become even more acute.

In the more distant future we will experiment with a "journal club," where selected authors will be asked to summarise their paper, placing it in the context of existing knowledge and how it might change current practice. The electronic format may also allow "chat rooms" on topics of particular interest or controversy. Conference reporting will also be quicker and more direct. We will experiment in summarising some of the more important presentations in Power Point format. The electronic format will also make it easier to expand the "From bench to bedside" (basic science for the clinician) series. 
The paper $S T I$ will initially mirror the electronic form in its essential outlines, but with some streamlining. We will try and banish long, indigestible, tables to STI Online. The "Global views" section will have the abstract in paper form and a longer manuscript than at present in e-format. We will do the same for articles dealing with operational issues, with an important but geographically limited audience. This will come under the heading of "In practice". We will be able to make much more adventurous use of colour.

On a longer perspective we think the written journal will not only become slimmer, but it will change fundamentally in character from a journal of fact to something more like what one of our editorial board members called for-a "one stop" journal. One attendee at the brainstorming session, in answer to the question "what do you see the paper journal doing in the future?" after some thought came out with: "nothing!" That may be too revolutionary but it contains an inescapable truth. " $p S T P$ ", or for that matter "p-anything" will be unimaginably different from what you have in your hands as you read this-assuming you've got this far. If for no other reason than that there may be less money to take it to the printers! The $p S T I$ of the future may resemble a cross between TV Times, Sight and Sound, and the New York Review of Books. Experts summarising the state of the art, articles from STI and other journals abstracted with an expert's commentary placing it in the context of current knowledge and practice, regular commissioned short reviews of recent advances in specific areas, research methodology, debates, updated lists of websites of interest, etc . . .

It is an exciting world we are entering. I have agreed to stay on as editor till December 2002. We have already expanded the hanging committee and will need to make other adjustments to meet the new challenges. We are asking the editorial board to become actively involved in moulding the new journal. We hope, and believe, the changes will make $S T I$ even more useful to you, the reader. Yet without your input these thoughts will be like raw eggs, nourishing, but crude. So please let us have your views-"p" or "e"!

MOHSEN SHAHMANESH

Editor, STI

1 About HighWire Press. Highwire.stanford.edu/about.shtlm

In attendance were Michelle Dimler, Tony Delamothe, Sarah Edwards, Richard Lau, Rob Miller, Janet O'Flaherty, Jonathan Ross, Mohsen Shahmanesh, Helen Ward, Alex Williamson, and Jonathan Zenilman (by phone). Annemiek de Ruiter and Simon Barton could not attend but sent their views.

\section{Sexually transmitted infections in women who have sex with women: who cares?}

What is known about the occurrence of sexually transmitted infections (STI) in women who have sex with women (WSW), and should it matter? Demographically, this is not a trivial issue: estimates of lifetime same sex behaviour among women range from $8 \%$ to $20 \%$, and between $1.4 \%$ and $4.3 \%$ of all women may be WSW on the basis either of behaviour or self defined identity. ${ }^{1-3}$ WSW have traditionally been viewed as "low risk" for STI, including HIV, and data from several small studies seem to support this belief..$^{4-9}$ However, as is often the case when one attempts to categorise any group by a descriptive "measurement" as complex as sexual behaviour, the real situation is of course more complicated.

As several studies have reported, the sexual practices of WSW present a reasonable means for vagina to vagina transmission of infected cervicovaginal secretions, ${ }^{10-12}$ a concept most directly supported by documentation of trichomoniasis being sexually transmitted between women..$^{13}$ There is strong evidence that transmission of human papillomavirus (HPV) between female sex partners occurs, as HPV and associated squamous intraepithelial lesions (SIL) have been detected in WSW who reported no previous sex with men. ${ }^{1415}$ Bacterial vaginosis (BV), a condition associated with pelvic inflammatory disease and adverse outcomes of pregnancy, ${ }^{16}$ occurs in $24 \%$ to $51 \%$ of WSW, ${ }^{91217} 18$ and sexual transmission of some responsible factor has been debated. ${ }^{12}{ }^{17}$ Although uncommon, transmission of HIV and hepatitis B between female sex partners has been reported. ${ }^{19-23}$ Many WSW are also at risk for STI acquisition from male partners. Even when surveyed outside STI clinic settings, most WSW report having had sex with men, and many $(20-30 \%)$ continue to have sex with men as well as women. ${ }^{24}$ Female adolescents who have sex with other females may be especially likely to engage in unprotected sex with both male and female partners. ${ }^{25}$
In this issue of Sexually Transmitted Infections, Fethers and colleagues report ( $\mathrm{p}$ 345) a case-control study of 1432 WSW attending a public STI and HIV clinic in Sydney for routine sexual health screen. ${ }^{26}$ Almost one in 10 women attending these clinics were WSW; only two thirds of these were screened for STI. Why those unscreened sought care at the clinic, and what determinants went into the decision not to screen them, is not described. More common among WSW relative to matched heterosexual controls were BV, previous diagnosis of STI, and seropositivity to hepatitis B and $\mathrm{C}$; less common was a report of previous genital warts. Equally prevalent were gonorrhoea, chlamydia, HIV, and Papanicolaou smear evidence of SIL. Trichomonas vaginalis, Chlamydia trachomatis, and HIV infections were detected in WSW reporting sex exclusively with women in the previous year. WSW more commonly reported having had sex with men who have sex with men (MSM) and injecting drug users (IDU), as well as a higher number of lifetime partners, ever having exchanged sex for money, and being IDU themselves. As the authors note, the prevalence of $\mathrm{BV}(8 \%)$ was low relative to that seen in other studies of WSW, possibly because one third of WSW attending the clinic were not screened for BV.

This report is important for two major reasons. Firstly, while case-control studies have their own set of limitations, they offer one approach to circumvent some of the methodological challenges inherent in studying WSW. As eloquently reviewed in a discussion on research in sexual minorities by a multidisciplinary task force report on lesbian, "gay," bisexual, and transgendered health, ${ }^{27}$ the methodological considerations underlying population selection, subject sampling, and recruitment are complex. Precisely defining a reproducible study group, while simultaneously acknowledging and accounting for the inherent heterogeneity in most populations, is especially challenging when studying 
sexual behaviour and its attendant risks and outcomes. Well controlled studies in reproducible populations can surmount some of these challenges; the case-control methodology employed by Fethers and colleagues in studying their STI clinic population is a good example.

Secondly, and more importantly, this is now the third study to show an alarming prevalence of HIV related risk behaviours in WSW who report sex with men during a visit to an STI clinic. These risks include sex with homosexual or bisexual men, use of injection drugs and of crack cocaine, and exchange of sex for drugs or money. ${ }^{28}{ }^{29}$ In our analysis of WSW attending our STI clinic in Seattle, Washington, WSW who reported sex with both male and female partners in the preceding 2 months had a high prevalence of risk behaviour for HIV acquisition, and women reporting sex only with other women in the preceding 2 months more commonly reported ever having had sex with a homosexual or bisexual man. ${ }^{29}$ Further, among $550 \mathrm{WSW}$ queried in a community survey done in San Francisco, $40 \%$ reported unprotected vaginal or anal sex with men during the past 3 years, including men who had sex with men and male IDU. ${ }^{30}$ A large, cross sectional, community based study of sociometric networks among IDU found that same sex behaviour among women was independently associated with a twofold increase in the likelihood of HIV infection. ${ }^{31}$ Thus, the proportion of HIV infected women who have sex with women may be substantial, while use of barrier methods to prevent STI transmission in such encounters may be low. ${ }^{32}$ In summary, these WSW could theoretically function as a "bridge" population: one with sexual links to men (possibly men at higher risk for STI/HIV by virtue of either being IDU or having sex with other men) and to WSW who are sexually active only with women. Such exposures could prove significant for WSW who may be classified as "low risk" when they later report exclusive same sex behaviour.

Despite this provocative and diverse evidence, we have only a limited understanding of the frequency and range of behaviours that put WSW at risk for STI acquisition, and no generalisable estimates of the epidemiology of STI in WSW. Why don't we know more? Attempts to use national or local surveillance data to estimate the prevalence of STI among WSW are limited in that many risk classifications have either excluded same gender sex among women or subsumed it under a hierarchy of other behaviours viewed as conferring greater risk. ${ }^{33}$ Few STI reporting systems routinely collect information on same sex behaviour among women. The situation is further complicated by the question of whether sexual minority women receive appropriate preventive health care, ${ }^{34}{ }^{35}$ and thus are even likely to access systems which might capture incident STI or consequent syndromes. For example, WSW probably do not receive Papanicolaou smear screening according to recommended guidelines; whether this relates to erroneous beliefs about personal risk for HPV and cervical cancer, or because providers do not appropriately screen WSW, is not known. ${ }^{103637}$

What are the challenges and tasks for those working in this area and those responsible for directing STI research and policy? As noted by Fethers and colleagues, traditional assumptions about the sexual practices between women have generally implied that such activities confer low or no risk. Such generalisations are often made categorically, without specific knowledge of sexual practices. At best, they are informed by disinterest, or by a lack of willingness to believe that the area is worthy of further study; at worst, homophobia and sexism contribute to these views. Such premature conclusions about STI risk among WSW adversely affect our ability to gather data that would illuminate our lack of knowledge. This "early closure" is deleterious not only for research directly related to STI in WSW; in large studies of more "traditional" health outcomes, such as breast cancer and heart disease, data on sexual orientation are not routinely collected despite the importance of measurements related to women's reproductive health histories. A tendency to dismiss the value of studying STI in WSW may certainly adversely affect the likelihood that research proposals are funded, and that research findings are published in journals with relatively wide readership in the scientific community.

Why study STI in WSW? Reasons for testing any scientific hypothesis should not be because it is politically mandated, because it is politically expedient, or because "it hasn't been studied." Research and funding priorities should be based on sound hypotheses and solid data. In the United States, the Institute of Medicine report on research priorities for lesbian health confirmed the need for more extensive data on sexual practices and healthcare seeking behaviours that put women who have sex with women at risk for STI ${ }^{38}$ The work of Fethers and colleagues adds to the growing body of evidence that supports this line of scientific inquiry. It also reminds us that our attempts to categorise people by "sexual behaviour" into risk groups that neatly predict STI epidemiology and transmission must account for the complexity and subtleties that characterise human sexual behaviour.

JEANNE M MARRAZZO

Department of Medicine, University of Washington, Seattle, WA, USA

1 Laumann EO, Gagnon JH, Michael RT, et al. Homosexuality. In: The social organization of sexuality: sexual practices in the United States. Chicago and London: University of Chicago Press, 1994; chapter 8:295.

2 Sell RL, Wells JA, Wypij D. The prevalence of homosexual behavior and attraction in the United States, the United Kingdom and France: results of national population-based samples. Arch Sex Behav 1995;24:235-48.

3 Johnson AM, Wadsworth J, Wellings $\mathrm{K}$, et al. Sexual attitudes and lifestyles. Oxford: Blackwell Scientific Publications, 1994.

4 Robertson P, Schachter J. Failure to identify venereal disease in a lesbian popertson P, Schachter J. Fallure to iden. Sex Transm Dis 1981;8:75-6.
population.

5 Edwards A, Thin RN. Sexually transmitted diseases in lesbians. Int f STD AIDS 1990;1:178-81.

AIDS 1990;1:178-81.
6 Petersen L, Doll L, White C, et al. No evidence of female-to-female transmission among 960,000 female blood donors. F Acquir Immune Defic Syndr 1992;5:853-5

7 Cohen $\mathrm{H}$, Marmor M, Wolfe R, et al. Risk assessment of HIV transmission among lesbians. F Acquir Immune Defic Syndr 1993;6:1173-4.

8 Raiteri R, Fora R, Sinicco A. No HIV-1 transmission through lesbian sex [letter]. Lancet 1994;344:270.

9 Evans BA, Kell PD, Bond RA, et al. Racial origin, sexual lifestyle, and genital infection among women attending a genitourinary medicine clinic in London (1992). Sex Transm Inf 1998;74:45-9.

10 Marrazzo JM, Stine K, Kuypers J, et al. Genital human papillomavirus in women who have sex with women. F Infect Dis 1998;178:1604-9.

11 Diamant AL, Lever J, Schuster MA. Lesbians' sexual activities and efforts to reduce risks for sexually transmitted diseases. $\mathcal{F}$ Gay Lesbian Med Assoc 2000;4:41-8.

12 McCaffrey M, Varney P, Evans B, et al. Bacterial vaginosis in lesbians: evidence for lack of sexual transmission. Int f STD AIDS 1999;10:305-8.

3 Kellock DJ, O'Mahony CP. Sexually acquired metronidazole-resistant trichomoniasis in a lesbian couple. Genitourin Med 1996;72:60-1

14 O'Hanlan KA, Crum CP. Human papillomavirus-associated cervical intraepithelial neoplasia following exclusive lesbian sex. Obstet Gynecol 1996;88:702-3.

15 Ferris DG, Batish S, Wright TC, et al. A neglected lesbian health concern: cervical neoplasia. F Fam Pract 1996;43:581-4.

16 Hillier SL, Nugent RP, Eschenbach DA, et al. Association between bacterial vaginosis and preterm delivery of a low-birth-weight infant. $N$ Engl f Med 1995;333:1737-42

17 Berger BJ, Kolton S, Zenilman JM, et al. Bacterial vaginosis in lesbians: a sexually transmitted disease. Clin Infect Dis 1995;21:1402-5.

18 Marrazzo JM, Koutsky LA, Stine K, et al. Prevalence and microbiology of bacterial vaginosis in lesbians. Sexually transmitted infections at the millennium, Baltimore MD, May 2000; abstract no 80

19 Troncoso AR, Romani A, Carranza CM, et al. Probable HIV transmission by female homosexual contact. Medicina B Aires 1995;55:334-6.

20 Rich JD, Buck A, Tuomala RE, et al. Transmission of human immunodeficiency virus infection presumed to have occurred via female homosexual contact. Clin Infect Dis 1993;17:1003-5.

21 Marmor M, Weiss LR, Lynden M, et al. Possible female to female transmission of HIV [letter]. Ann Intern Med 1986;105:969.

22 Monzon OT, Capellan JMB. Female-to-female transmission of HIV. Lancet 1987;2:40-1.

23 Hofmann J, Marrazzo JM. Hepatitis B sexually transmitted between women (submitted).

24 Diamant AL, Schuster MA, McGuigan K, et al. Lesbians' sexual history with men: implications for taking a sexual history. Arch Intern Med 1999;159:2730-6. 
25 Saewyc EM, Bearinger LH, Blum RW, et al. Sexual intercourse, abuse and pregnancy among adolescent women: does sexual orientation make a 999;31:127-31.

26 Fethers K, Marks C, Mindel A, et al. Sexually transmitted infections and risk behaviours in women who have sex with women. Sex Transm Inf $2000 ; 76: 345-9$

27 Center for Lesbian, Gay, Bisexual and Transgender Health, Columbia University. Lesbian, gay, bisexual, and transgendered health: findings and concerns. January 2000 .

28 Bevier PJ, Chiasson MA, Heffernan RT, et al. Women at a sexually transmitted disease clinic who reported same-sex contact: their HIV seroprevalence and risk behaviors. Am f Public Health 1995;85:1366-71.

29 Marrazzo JM, Handsfield HH. Characteristics of female sexually transmitted disease clinic clients reporting same-sex behavior, 1993-1997 Int $\mathcal{F}$ STD AIDS (in press)

30 Lemp GF, Jones M, Kellogg TA, et al. HIV seroprevalence and risk behaviors among lesbians and bisexual women in San Francisco and Berkeley, California. Am f Public Health 1995;85:1549-52.

31 Friedman SR, Neaigus A, Jose B, et al. Sociometric risk networks and risk for HIV infection. Am f Public Health 1997;87:1289-96.
32 Gonzales V, Washienko KM, Krone MR, et al. Sexual and drug-use risk factors for HIV and STDs: a comparison of women with and without bisexual experiences. Am f Public Health 1999;89:1841-6.

33 Kennedy MB, Scarlett MI, Duerr AC, et al. Assessing HIV risk among women who have sex with women: scientific and communication issues. $\mathcal{F}$ Am Med Women's Assoc 1995;50:103-7.

34 Carr SV, Scoular A, Elliott L, et al. A community-based lesbian sexual health service- clinically justified or politically correct? Br f Fam Plann 1999: 93-5.

35 Smith EM, Johnson SR, Guenther SM. Health care attitudes and experiences during gynecologic care among lesbians and bisexuals. $A m \mathcal{F}$ Public Health 1985;75:1086-7.

36 O'Hanlan KA. Lesbian health and homophobia. Curr Prob Obstet Gynecol Fertil 1995;18:93-136.

37 American Medical Association, Council on Scientific Affairs. Health care needs of gay men and lesbians in the United States. FAMA 1996;275:13549.

38 Institute of Medicine. Lesbian health: current assessment and directions for the future. Washington DC: National Academy Press, 1999.

\section{Postal research: too many problems?}

Postal research is a valuable means of collecting health related information. Although the majority of mailed research is in the form of questionnaires, postal services have also been used to report the results of home tests or to obtain clinical specimens. ${ }^{1-7}$ This approach has been shown to be valuable in certain screening programmes. For example, home testing for glycosuria and subsequent reporting of the results is a simple and effective way of population screening for diabetes mellitus. ${ }^{1}$ For genitourinary medicine physicians the concept of postal screening may provide an acceptable method of screening low risk populations for certain sexually transmitted infections. A number of studies have already investigated the potential for postal screening for Chlamydia trachomatis infection using mailed specimens including first void urine and vaginal flush samples. ${ }^{3-7}$

On the surface, postal research would appear to provide a simple, cost efficient means of reaching a widely dispersed population, many of whom would not normally attend a healthcare setting. However, there are a number of factors that need to be considered in the design of the survey and careful interpretation of the information obtained is essential to ensure the validity of results.

\section{Response rates}

One of the major problems with mailed research is that response rates tend to be low. Response rates will vary depending on the type of survey and the persistence of the investigators in terms of both the number and type of contacts with the subjects. ${ }^{1389}$

Higher response rates are seen when repeat mailings are sent to subjects. In their study investigating non-response bias in postal surveys, Tennant and Badley report an $87 \%$ response rate after four mailings of the survey. ${ }^{8}$ The first mailing saw a $57 \%$ response, increasing to $73 \%$ after the second mailing and $81 \%$ after the third.

Macleod et al surveyed a mixed population of 200 subjects, requesting mailed urine samples to screen for $C$ trachomatis infection. ${ }^{3}$ They report a response rate of $93 \%$ from the $68 \%$ of the original subject group who were confirmed to be resident at the address registered with their general practitioner. To achieve this response rate they sent out two mailed packages by recorded delivery and subsequently telephoned or visited non-responders.

The request made by the study can influence participation. Etter $e t a l^{9}$ set out to establish whether asking subjects to provide a saliva sample in conjunction with a survey would influence response rate. They found an $11 \%$ lower response rate than when participants were asked only to complete a questionnaire related to smoking habits. It was proposed that the lower response may have arisen as a result of participants' concern that tests other than those specified may have been performed on the samples, such as HIV testing or drug screening. Alternatively, participants may not have felt adequately compensated for providing a specimen.

A low response rate will also be seen if address databases are not regularly updated, particularly where highly mobile populations such as students are being surveyed. Macleod et $a l^{3}$ reported that $32 \%$ of subjects aged $18-45$ were no longer living at their GP registered address in their postal survey. Others have also reported the inadequacy of family practitioner committees' lists, and noted that screening programmes will fail if population registers are not improved. ${ }^{10}$

\section{Incentives}

Numerous incentives designed to improve response rates have been evaluated, and it would appear that a combination of these incentives is most effective.

Spry et $a l^{11}$ found that prenotification in combination with a lottery incentive significantly improved response rates and that prenotification by telephone, although more expensive, was more effective than by postcard. The lottery incentive alone did not increase response rates significantly. Reminders in the form of a letter or postcard, or as a repeat mailing of the questionnaire, have been shown to increase response. This effect tends to decline after the second mailing. ${ }^{11}$

It is generally perceived that shorter questionnaires are more likely to be completed than longer ones, and some investigators reduce the length of questionnaires in an attempt to enhance response at the expense of the amount of information obtained. However, Spry et $a l^{11}$ compared an eight page survey with a two page survey and found that the length of these questionnaires did not appear to influence response rates. Hoffman et $a l^{12}$ found similar results.

A meta-analysis of mail survey response rate by Fox et al reported that the largest increase in response rate was seen with university sponsorship of the study, prenotification by letter, and stamped return postage.$^{13}$ First class outgoing postage and the colour of the questionnaire were other factors identified. 
Table 1 International Air Transport Association 602 Packaging Regulations: a summary of the main recommendations

- $\quad$ Primary receptacles (specimen containers) must be glass, metal, or plastic and resistant to any chemical or other action of the sample. Seals must be leak proof - eg heat seal, skirted stopper, metal crimp seal. Screw caps, if used, must be reinforced with overtape.

- The primary container should be surrounded with sufficient material to absorb the entire contents of the primary receptacles. Multiple samples must be individually wrapped. This must be packed in a watertight secondary container.

- The secondary receptacles must not contain more than $50 \mathrm{ml}$ or $50 \mathrm{~g}$.

- The outer packaging must be of adequate strength and at least $100 \mathrm{~mm}$ in the smallest overall external dimension.

- An itemised list of contents (pathology forms) must be placed between the secondary and outer packaging.

Outer labelling must include:

- A Class 6 transport label for infectious substances.

- UN packaging specification marks.

- The name and address of the sender, the recipient, and a contact name and emergency number.

- A shipping name label.

It is important to note that incentives that are effective in one population may not be transferable to another. A number of postal surveys have incorporated in their design a means of investigating which incentives provide the best response. A "randomised phase" is initially undertaken and analysed. The incentive inducing the greatest response is then adopted for the "most effective intervention" stage of the survey. ${ }^{14}$

\section{Bias in postal surveys}

As with any other study, bias can influence the results of postal surveys. Sampling bias can be introduced to a postal survey if subjects selected are not truly representative of the population targeted. The study may aim to represent the general population-for example, subjects selected from GP patient lists, or a select population such as university students or adolescents attending a genitourinary medicine clinic. Sampling techniques and random selection procedures are used to determine a representative study sample. Within that sample, certain people may be more likely to respond to a particular survey than others. This may result in selection of a subset of the targeted population being represented.

The possibility of incentives introducing bias needs to be considered. Incentives may introduce selection bias by encouraging a certain subgroup of the population to respond to the survey, or they may introduce information bias by influencing the participants' responses.

\section{Prevalence studies}

The objective of many postal surveys is to determine prevalence. Incomplete response to a survey can introduce uncertainty as to the true prevalence of a condition. Simple extrapolation of the results assumes that there is no difference in prevalence between the responders and the non-responders and consequently may lead to an underestimation or overestimation of the prevalence. This may be particularly important in surveys dealing with sexually transmitted infections where the prevalence of a condition may be strongly influenced by a small "core group" at high risk of acquiring an STI. If this group is underrepresented or overrepresented among respondents there will be a significant impact on the results.

\section{Mailing clinical specimens}

There are specific issues which need to be addressed when requesting clinical specimens from subjects via the postal services. However, few studies that have involved the postage of pathological specimens have described the packaging used during transport. A discussion of this would aid future researchers aiming to undertake similar studies.
In order for clinical specimens to be carried by postal services in the United Kingdom, the Royal Mail currently require packaging to comply with the International Air Transport Association (IATA) Dangerous Goods regulations and use UN packing instructions 602 for the carriage of samples likely to contain infectious substances and those for microbiological analysis. These regulations apply to all countries. Some countries such as the United States also have their own national regulations. Of note with the new 602 packaging is the specification that the external dimensions of the package must be a minimum of $100 \mathrm{~mm}$ in the smallest overall dimension (table 1). This is too large to allow posting though a normal letter box, necessitating that packages are collected from and delivered to a post office, or that a courier service is used. This may prove to deter subjects from participating in studies. Future postal surveys involving specimen collection will also be more expensive than those previously conducted. However, there is currently a debate as to whether these regulations are necessary for all diagnostic specimens. The formerly used UN 650 packaging specifications can be compact enough to allow postage and may still provide sufficient safety for transport of these specimens.

\section{Sampling and diagnostic accuracy}

Posting of specimens can affect the reliability of certain diagnostic tests. Dabbs ${ }^{2}$ found that using cotton rolls rather than chewing gum for collection of saliva specimens resulted in an elevation of testosterone levels on testing. Posting of the specimens resulted in an elevation of female salivary testosterone levels, but not those from male subjects. Adequate investigation needs to be undertaken to ensure that factors such as unpredictable temperature storage, delays in collection, and the transport medium for the specimen will not adversely affect the test results.

Parker et $a l^{15}$ assessed the stability of specimens from 1017 women for chlamydia testing by Gen-Probe PACE 2 sent via the US postal system compared with those transported in a controlled environment (by courier). They reported a $99 \%$ agreement in results between the two groups even after $50 \%$ of the mailed specimens had been subjected to temperatures above $31^{\circ} \mathrm{C}$ and $44 \%$ had been in transit for more than 3 days. These data suggest that swabs remain stable during postal transit, but these findings may not apply to other specimens such as urine.

For studies of sexually transmitted infections, specimens from the urogenital tract are usually required. Consideration therefore needs to be given to the subjects' ability and willingness to provide such specimens and to how comparable the sensitivity and specificity of self testing compares with physician obtained samples. Ostergaard et $a l^{5}$ found that the diagnostic efficacy of home obtained and mailed vaginal flush and urine specimens was comparable with physician obtained and mailed endocervical and urethral swabs when testing was by ligase chain reaction.

\section{Ethical issues}

Obtaining ethical approval for postal surveys can be difficult, especially when the survey covers a large geographical area involving numerous committee - for example, with national questionnaires. The requirements of each individual ethics committee may vary, resulting in numerous submissions and the associated administration and time costs. This is aptly described by Middle et al who completed 1095 protocols and 1116 application forms to undertake a postal survey of a sample of children born in 1988 in England and Wales. ${ }^{16}$ Although the newly formed multicentre research ethics committee simplifies the procedure, submissions to local ethics committees are still required. 
Another ethical issue that arises when asking participants to provide a clinical sample for a specified test or to report a test result is how to contact the respondent in the event of a positive result. If participants are asked to provide contact details and do not do so, or are not contactable from the information given, the investigators can be left in a difficult position. The participant will be expecting to be contacted if the test result is significant, but on the other hand may consider further action by the investigator (for example, contacting their general practitioner) a breach of confidentiality. Such issues need to be given considerable thought before embarking on such studies.

Postal survey can provide valuable information relating to health issues. However, the design of the study needs to minimise the introduction of bias and give adequate consideration to ethical and practical issues.

Copies of the IATA Dangerous Goods Regulations, 41st edition, 2000, and the IATA Infectious Substances Shipping Guidelines detailing the IATA 602 packaging regulations can be purchased from Danvers International, 36 Court House Road, Finchley, London N12 7PJ, UK (tel: +44 (0) 208445 3929; fax: +44 (0) 2084452745$)$.

$S$ M BATES

K E ROGSTAD

Department of GU Medicine, Royal Hallamshire Hospital, Sheffield

S10 27F, UK

sylvia.bates@csoh.nhs.uk

1 Davies $\mathrm{M}$, Alban-Davies $\mathrm{H}$, Cook C, et al. Self testing for diabetes mellitus. BMF 1991;303:696-8.
2 Dabbs JM. Salivary testosterone measurements: collecting, storing, and mailing saliva samples. Physiol Behav 1991;49:815-17.

3 Macleod J, Rowsell R, Horner P, et al. Postal urine specimens: are they a feasible method for genital chlamydia infection screening? Br f Gen Pract 1999;49:455-8.

4 Moller JK, Andersen B, Olesen F, et al. Impact of menstrual cycle on the diagnostic performance of LCR, TMA, and PCE for detection of Chlamydia trachomatis in home obtained and mailed vaginal flush and urine samples. Sex Transm Inf 1999;75:228-30.

5 Ostergaard L, Moller JK, Andersen B, et al. Diagnosis of urogentital Chlamydia trachomatis infection in women based on mailed samples obtained at home: multipractice comparative study. BMF 1996;313:1186-9.

6 Andersen B, Ostergaard L, Moller JK, et al. Home sampling versus conventional contact tracing for detecting Chlamydia trachomatis infection in male partners of infected women: randomised study. BMF 1998;316:3501 in

7 Ostergaard L, Andersen B, Loesen F, et al. Efficacy of home sampling for screening of Chlamydia trachomatis: randomised study. BMF 1998;317: 26-7.

8 Tennant A, Badley EM. A confidence interval approach to investigating non-response bias and monitoring response to postal questionnaires. $\mathcal{F} E p i$ demiol Community Health 1991;45:81-5.

9 Etter J-F, Perneger TV, Ronchi A. Collecting saliva samples by mail. Am $\mathcal{F}$ Epidemiol 1998;147:141-6.

10 Bowling A, Jacobs B. Screening: the inadequacy of population registers. BMF 1989;298:545-6.

11 Spry VM, Hovell MF, Sallis JG, et al. Recruiting survey respondents to mailed surveys: controlled trials of incentives and prompts. Am 7 Epidemiol 1989;130:166-72.

12 Hoffman SC, Burke AE, Helzlsouer KJ, et al. Controlled trial of the effect of length, incentives, and follow-up techniques on response to a mailed questionnaire. Am F Epidemiol 1998;148:1007-11.

13 Fox JR, Crask MR, Kim J. Mail survey response rate: a meta-analysis of selected techniques for including response. Public Opin $Q$ 1988;52:467-91.

14 Perneger TV, Etter J-F, Rougemont A. Randomised trial of use of a monetary incentive and a reminder card to increase the response rate to a mailed health survey. Am f Epidemiol 1993;138:714-22.

15 Parker EK, Wokniak A, White SD, et al. Stability study in specimens mailed to a state laboratory and tested with the gen-probe PACE 2 assay for to a state laboratory and tested with the gen-pr
chlamydia. Sexually Transm Dis 1999; 26:123-5.

16 Middle C, Johnson A, Petty T, et al. Ethics approval for a national postal survey: recent experience. BMF 1995;311:659-60. 